\title{
A Mining/Contained Explosion Source Phenomenology Experiment To Improve Nuclear Test Monitoring
}

W.R. Walter, M. Denny, C. Pearson, S.C. Myers

\section{January 13, 2000}

U.S. Department of Energy

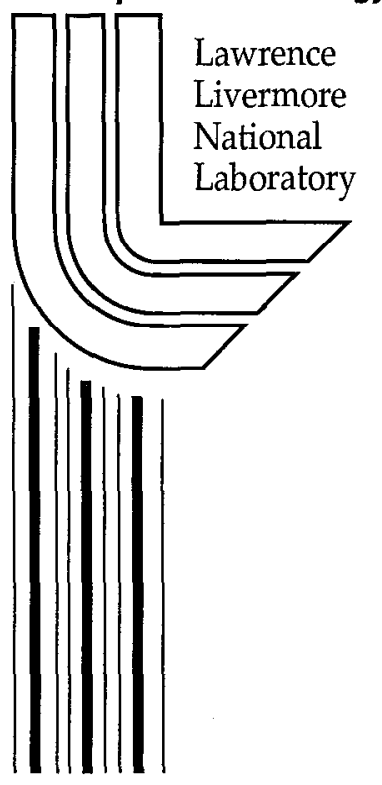




\section{DISCLAIMER}

This document was prepared as an account of work sponsored by an agency of the United States Government. Neither the United States Government nor the University of California nor any of their employees, makes any warranty, express or implied, or assumes any legal liability or responsibility for the accuracy, completeness, or usefulness of any information, apparatus, product, or process disclosed, or represents that its use would not infringe privately owned rights. Reference herein to any specific commercial product, process, or service by trade name, trademark, manufacturer, or otherwise, does not necessarily constitute or imply its endorsement, recommendation, or favoring by the United States Government or the University of California. The views and opinions of authors expressed herein do not necessarily state or reflect those of the United States Government or the University of California, and shall not be used for advertising or product endorsement purposes.

Work performed under the auspices of the U. S. Department of Energy by the University of California Lawrence Livermore National Laboratory under Contract W-7405-Eng-48.

This report has been reproduced

directly from the best available copy.

Available to DOE and DOE contractors from the

Office of Scientific and Technical Information

P.O. Box 62, Oak Ridge, TN 37831

Prices available from (423) 576-8401

http://apollo.osti.gov/bridge/

Available to the public from the

National Technical Information Service

U.S. Department of Commerce

5285 Port Royal Rd.,

Springfield, VA 22161

http://www.ntis.gov/

OR

Lawrence Livermore National Laboratory

Technical Information Department's Digital Library

http://www.llnl.gov/tid/Library.html 


\title{
A Mining/Contained Explosion Source Phenomenology Experiment To Improve Nuclear Test Monitoring
}

\author{
W. R. Walter, M. Denny, C. Pearson* and S. C. Myers \\ Lawrence Livermore National Laboratory \\ * Los Alamos National Laboratory \\ DOE Nuclear Test Monitoring Research and Engineering Program
}

\section{Summary}

We propose an experiment to investigate the similarities and differences in source phenomenology and regional seismic discriminant behavior between normal production mining explosions and fully contained nuclear tests. The experiment would consist of a minimum of two large, nearly co-located explosions, which would be recorded at regional distances: 1) a normal delay fired production mining explosion, and 2) a single chemical explosion contained and buried at underground nuclear test depth.

\section{Background}

Regional distance seismic recordings of underground nuclear tests are quite rare and are limited mainly to the former test sites (see Figure 1). This poses a significant challenge to calibrating seismic discriminants at the new International Monitoring System (IMS) stations, or any new seismic stations. Many stations are either located beyond regional distances from past nuclear tests, or started operating after nuclear testing in the region ceased. Consequently, most of the existing and planned IMS stations, and any future stations, will need to be calibrated without any regional distance seismic recordings of underground nuclear tests.

While it is possible to develop models for transporting seismic discriminants from the nuclear test sites to analogous regions without nuclear tests, we also want to validate these discriminants with empirical data whenever possible. The largest potential source of empirical explosion data is from commercial mining operations. These produclion explosions are geographically widely distributed and often recorded at near regional distances. They also are another source of background seismicity that needs to be correctly identificd for nuclear test monitoring such as for the Comprchensive Nuclear-Test Ban Treaty (CTBT). If the relationship between normal production mining explosions and fully contained underground nuclear tests were clearly understood, these mining explosions could be used to help calibrate seismic stations, and "false alarms" from mining activity could be reduced.

To monitor for underground nuclear tests, seismic sensors will need to detect and differentiate between four types of explosions:

- $\quad \mathrm{CN}=$ Contained (underground) Nuclear Explosion

- $\quad \mathrm{CC}=$ Contained (underground) Chemical Explosion

- $\quad \mathrm{SC}=$ Surface Chemical Explosion (buried but not as contained as a CC)

- $\quad \mathrm{PM}=$ Production Mining Explosion (multiple shots in time and space)

Previous experiments have established relationships between some of these explosion types (e.g. Denny et al., 1996; Stump and Pearson, 1997; Myers et al., 1999):

- NPE -Establishes CN-CC equivalence for regional discriminants (except yields)

- Black Thunder - Looks at SC and PM relationship at one mine

- DOB (Kazakh) - Looks at CC versus SC for two material types 
The results of these experiments can be expressed in a matrix comparing explosion types:

\begin{tabular}{|c|c|c|c|}
\hline & CC/CN & SC & PM \\
\hline CC/CN & NPE & DOB & $?$ \\
\hline SC & & & Black Thunder \\
\hline PM & & & \\
\hline
\end{tabular}

We have used the NPE results, $\mathrm{CC}=\mathrm{CN}$, to combine these explosion types in the matrix. Note that the only missing cell is the one comparing $\mathrm{CC} / \mathrm{CN}$ and $\mathrm{PM}$ explosion types. The purpose of our proposed experiment is to fill in this critical knowledge gap by conducting a nearly co-located PM-CC experiment. By conducting the experiment we will examine (using the $\mathrm{CC}=\mathrm{CN}$ NPE results) the CN-PM differences to understand both the basic source phenomenology and the resulting regional discriminant performance. Such an experiment would address a definable phenomenology gap that if clearly understood would provide a more sound and complete physical basis for validating the transportability of discriminants using existing PM blasts.

\section{Regional Discriminant Behavior / Research Issues}

Previous research on Nevada Test Site (NTS) explosions, as well as other test site data and phenomenology experiments, show regional explosion discriminants have a large variability induced by several factors, including:

- Source region material properties and saturation

- Source depth and containment

- Tectonic release and focal mechanism

- Source configuration in time and space

- Scattering of phases such as $\mathrm{Rg}$ and $\mathrm{P}$ into $\mathrm{S}$ waves

The differences between production mining cxplosions and any future banned tests may involve differences in many or all of these factors interacting in a complex way. For example, production mining shots are designed to efficiently fracture rocks and thus may generate significantly more $\mathrm{S}$ waves than a single spherically symmetric shot. Some experiments at Black Thunder appear to confirm this idea, though the relative increase in S-wave energy is slight (Stump and Pearson, 1997). If this idea held true for most production mining explosions, then we could say with confidence that P/S earthquake/mining- explosion discrimination would give us conservative estimates of earthquake/nuclear- explosion discrimination since the nuclear tests would have even larger P/S ratios than the mining ones. Execution of the proposed experiment will directly test this assumption.

The 1997 Kazakhstan DOB experiment points out the importance of depth-of-burial on P/S ratio discriminants. In particular shallow shots generate large $\mathrm{Rg}$ phases that are believed to scatter and produce large $\mathrm{S}$ phases at some frequencies. This efficiency of the $\mathrm{Rg}$ scattering will depend on the local conditions such as geology and lopography. The Kazakh results lead us to predict that at lower frequencies like 2-4 $\mathrm{Hz}$ a CC or CN shot could have a $\mathrm{P} / \mathrm{S}$ value four times or more (Myers et al, 1999) as large as a SC shot, while at $6-8 \mathrm{~Hz}$ they would have similar $\mathrm{P} / \mathrm{S}$ values. Let's assume a slight increase, say $10 \%$, in $\mathrm{P} / \mathrm{S}$ ratio for the $\mathrm{SC}$ relative to $\mathrm{PM}$, since the multiple shots in the $\mathrm{PM}$ should generates more $\mathrm{S}$ waves than a single shot as discussed above. Under these assumptions we can use the Kazakh results to predict the P/S relationship of CC to PM shots. This idea is illustrated in Figure 2, where we have recorded mine blasts and earthquakes at an IMS station in Morocco. If this prediction were true it would allow us to go beyond saying PM data is a conservative test for $\mathrm{CC} / \mathrm{CN}$ and better predict discrimination performance. On the other hand, the prediction illustrated in Figure 2 is in disagreement with some $\mathrm{CN}$ observations that $\mathrm{P} / \mathrm{S}$ separation tends to improve as you go from $2-4 \mathrm{~Hz}$ up to the $6-8 \mathrm{~Hz}$ band (e.g. Walter et al. 1995). This 
proposed CC/PM experiment is needed to resolve this disagreement and directly test the extrapolation of the Kazakh and Black Thunder data for predicting the CC/CN and PM separation.

Regional discriminants based on low-to-high frequency ratios show an even larger variability than $\mathrm{P} / \mathrm{S}$ ratios. NTS data has demonstrated the strong sensitivity of these discriminants to source material properties. We would expect production-mining explosions to behave similarly. However the Kazakh depth of burial experiment has demonstrated that there is also a strong relationship between explosion $\mathrm{S}$ wave frequency content and depth of burial, at least for very shallow explosions. This proposed source phenomenology experiment could help us understand the complex interaction between material property, depth and containment on regional discriminants. Without such empirical data it is difficult to use cxisting low/high frequency earthquake/mining-blast discriminants to infer how a nuclear explosion would behave using the same discriminants. A major goal of this experiment is to allow us to make use of existing production-mining / earthquake discrimination results at stations of CTBT interest to infer how nuclear tests will discriminate from earthquakes and production-mining explosions at the same stations.

\section{Experimental Requirements / Design}

The basic experiment requires at least one large production-mining explosion and one large underground chemical explosion that are nearly co-located $(<1 \mathrm{~km})$. A schematic view is shown in Figure 3 . The production-mining explosion should be similar to those normally seen in that region. The shot layout, geology and results of the explosion need to be carefully documented in order to understand the phenomenology. Similarly, the underground chemical explosion needs to be buried at least as deep as the appropriate scaled depth nuclear explosion would be. In addition it needs to be fully contained, and made as similar to a single point source as possible. Again the geometry, geological material and surface effects of this shot need to be carefully documented to understand the source phenomenology. Previous work at Black Thunder confirms the capability of conducting an experiment of this type.

Both explosion types should be seismically detectable at near regional distances beyond the $\mathrm{Pn}-\mathrm{Pg}$ crossover distance (>150-250 km). To evaluate differences in the regional seismic discriminants will require that the appropriate regional phases be detectable over the normal regional bandwidth. Therefore the common regional phases $(\mathrm{Pn}, \mathrm{Pg}, \mathrm{Sn}, \mathrm{Lg}$ and coda) must have reasonable signal-to-noise over the 1-10 $\mathrm{Hz}$ frequency band.

For both practical and cost reasons we propose conducting the experiment in an existing mine that normally has production shots that are seismically visible at regional distances (e.g. Black Thunder).

\section{Experiment Goals}

The main goals of the proposed experiment are to understand production-mining (PM) versus concentrated chemical/nuclear explosion $(\mathrm{CC} / \mathrm{CN})$ discrimination differences:

- To directly compare empirical regional seismic waveform and discriminant differences with model predictions, such as:

- CC and PM regional seismic waveforms will have some significant differences (due to depth, material properties and source multiplicity)

- P/S discriminant ratios are higher for the CC than the PM (PM has rock fracturing, throw and shallower depth that enhance $\mathrm{Rg}$ to $\mathrm{S}$ scattering)

- To better understand the relative importance of depth and multiple shot effects in explosion source phenomenology.

- To use the results to improve nuclear test monitoring calibration efforts by allowing the use of recordings of existing mine blasts in regions of interest to test seismic discriminant transportability. 


\section{Schedule and Costs}

An anticipated schedule listed from date of approval and estimates of costs associated with special explosion (no DOE/UC personnel costs included):

- 1.0 month

- Contact mine(s), obtain written approval and/or MOU, begin contract negotiations for material and labor costs associated with drilling, emplacement and detonation of single fircd, custom designed calibration explosion.

- Complete initial draft of experiment plan and notification list.

- 1.5 month

- Complete final version of experiment plan and notification list, forward to DOE/HQ.

- 2.5 month (assuming contracting for material and labor costs can be completed in 1.5 months)

- Deploy seismic and infrasonic instrumentation locally (LANL) and regionally (LLNL).

- Document drilling, emplacement and detonation of single fired, custom designed calibration explosion. Acquire seismic and infrasonic data.

- Document drilling, emplacement and detonation typical multi-kiloton production cast blast. Acquire seismic and infrasonic data.

- Estimated contract costs for drilling, emplacement and detonation of fully contained, 100 ton, single fired, custom designed calibration explosion within $1 \mathrm{~km}$ of production cast blast: $\$ 230,000$.

- 3.5 month (assuming contracting for material and labor costs can be completed in 1.5 months)

- Complete initial draft of Quick Look report.

- Archive and distribute data.

- 4.5 month (assuming contracting for material and labor costs can be completed in 1.5 months)

- Complete Quick Look report and forward to DOE/HQ.

- Integrate local and regional seismic data into Knowledge Base.

- 6.0 month (assuming contracting for material and labor costs can be completed in 1.5 months)

- Complete initial draft of final report.

- 7.0 month (assuming contracting for material and labor costs can be completed in 1.5 months)

- Complete final experiment report, forward to DOE/HQ.

- Integrate results into Knowledge Base.

Acknowledgements. This work was performed under the auspices of the U. S. Department of Energy by the Lawrence Livermore National Laboratory, under contract W-7405-ENG-48.

\section{References}

Denny, M. D., P. G. Goldstein, K. Mayeda, and W. R. Walter, "Seismic results from DOE's NonProliferation Experiment: A comparison of chemical and nuclear explosions", in Monitoring a Comprehensive Test Ban Treaty, edited by E. S. Husebye and A. M. Dainty 355-364, Kluwer Academic Publishers, 1996.

Myers, S. C, W. R. Walter, K. M. Mayeda and L. Glenn, Observations in support of Rg scattering as a source for explosion $S$ waves: regional and local recordings of the 1997 Kazakhstan depth of burial experiment, Bull. Seism. Soc. Am., 89, 544-549, 1999. 
Stump, B. W. and D. C. Pearson, Comparison of single-fired and delay-fired explosions at regional and local distances, in Proceedings of the 19th Seismic Research Symposium on Monitoring a Comprehensive Test Ban Treaty, Defense Special Weapons Agency Report, 668-677, 1997.

Walter, W. R., D. B. Harris, and S. C. Myers, Seismic discrimination between earthquakes and explosions in the Middle East and North Africa, in Proceedings of the 19th Seismic Research Symposium on Monitoring a Comprehensive Test Ban Treaty, Defense Special Weapons Agency Report, 459-468, 1997.

Walter, W. R., K. M. Mayeda and H. J. Patton, Phase and spectral ratio discrimination between NTS earthquakes and explosions, part I: empirical observations, Bull. Seism. Soc. Am. 85, 1050-1067, 1995 


\section{The planned IMS stations and nuclear tests 1980-1998}

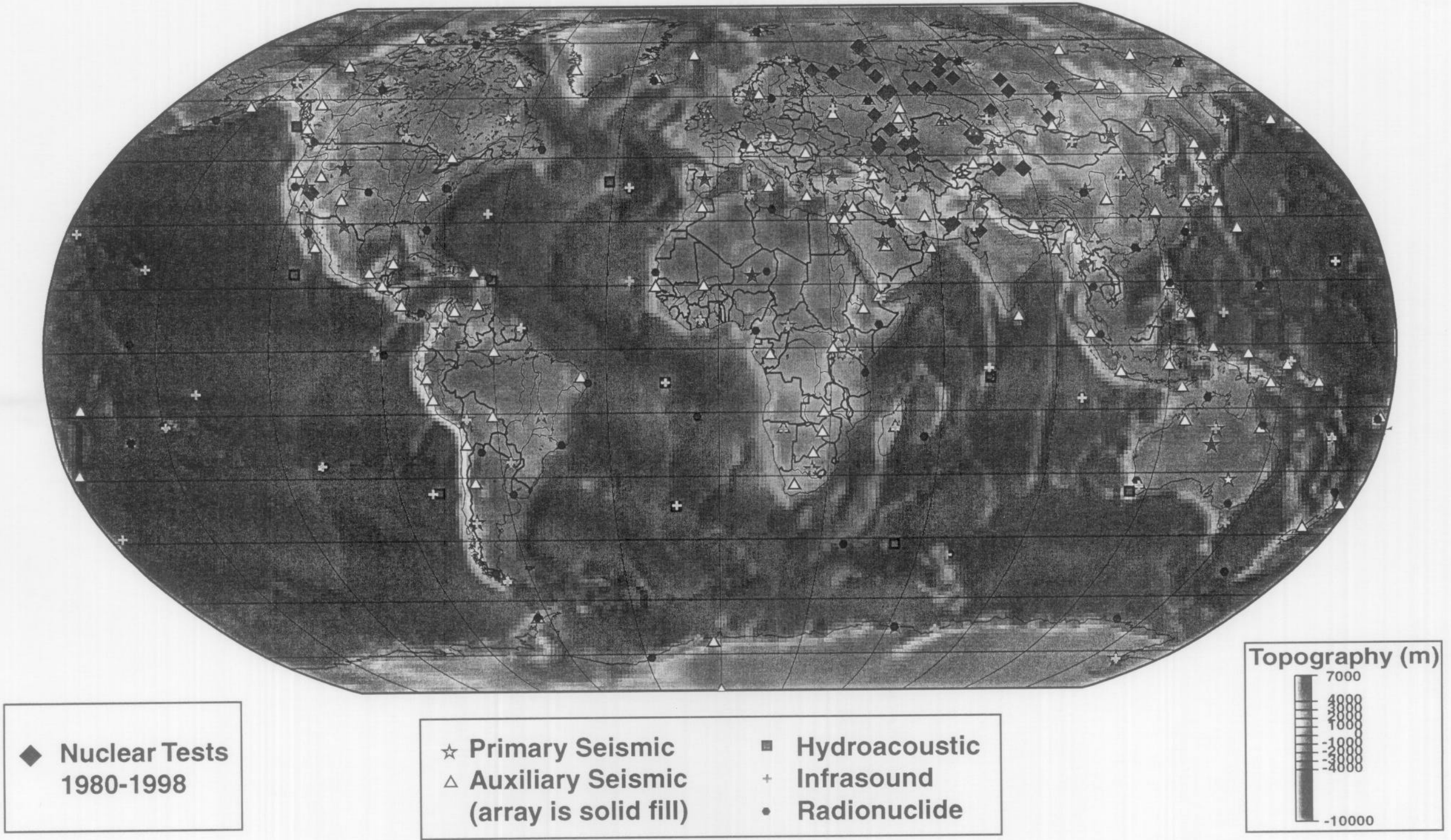

Fig. 1. Map showing the locations of the planned IMS network and nuclear tests since 1980, when digital data is more likely to be available. Note that nuclear tests are limited to the Former Soviet Union and the test sites of the the US, China, France, India and Pakistan, so regional digital recordings of nuclear tests are only possible in these regions. In addition many IMS stations were not in place when this testing occurred. Therefore most IMS stations will have to be calibrated without any regional distance recordings of nuclear tests. 


\section{Map of independently identified events}

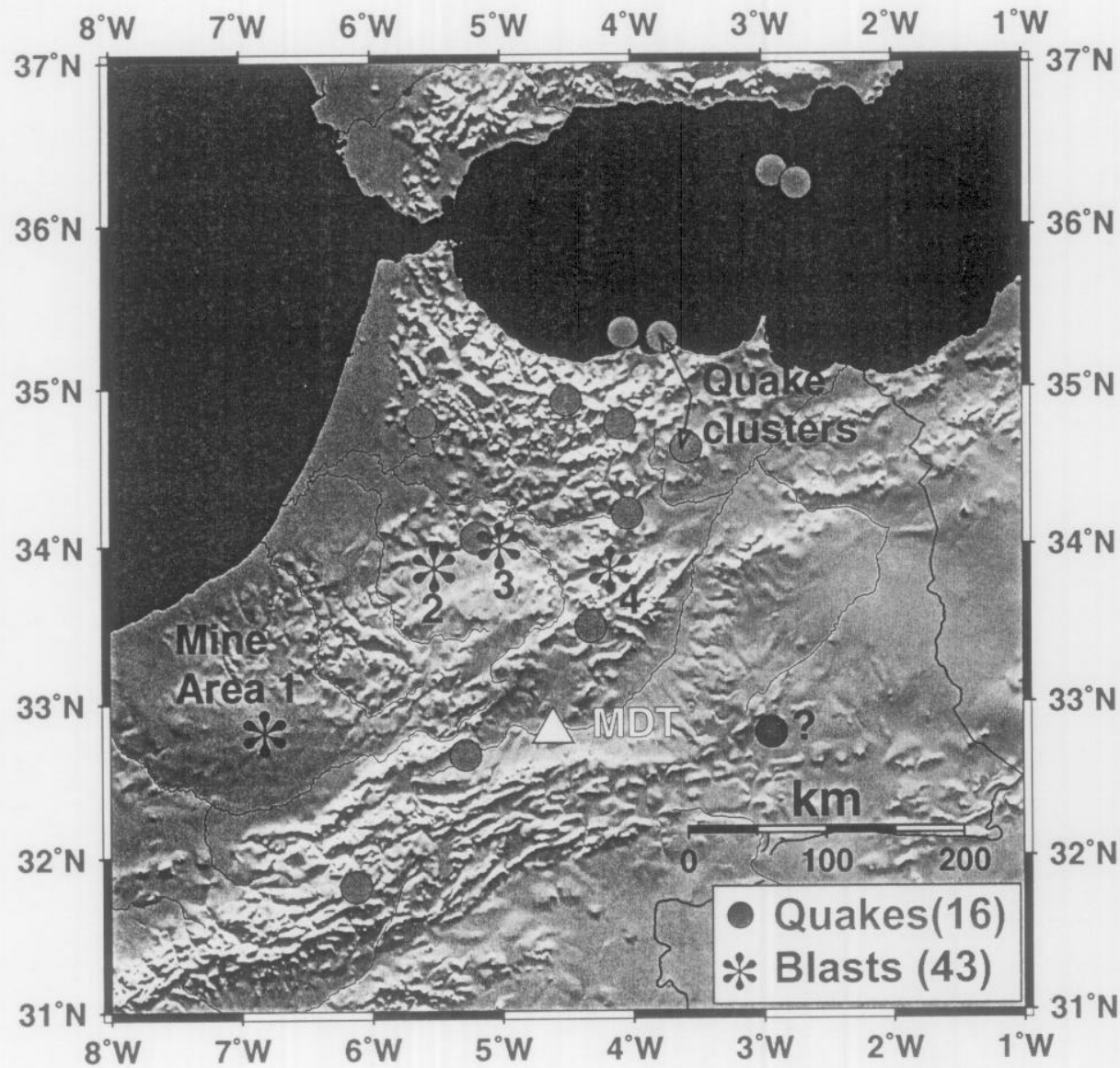

\section{Discrimination performance plots}
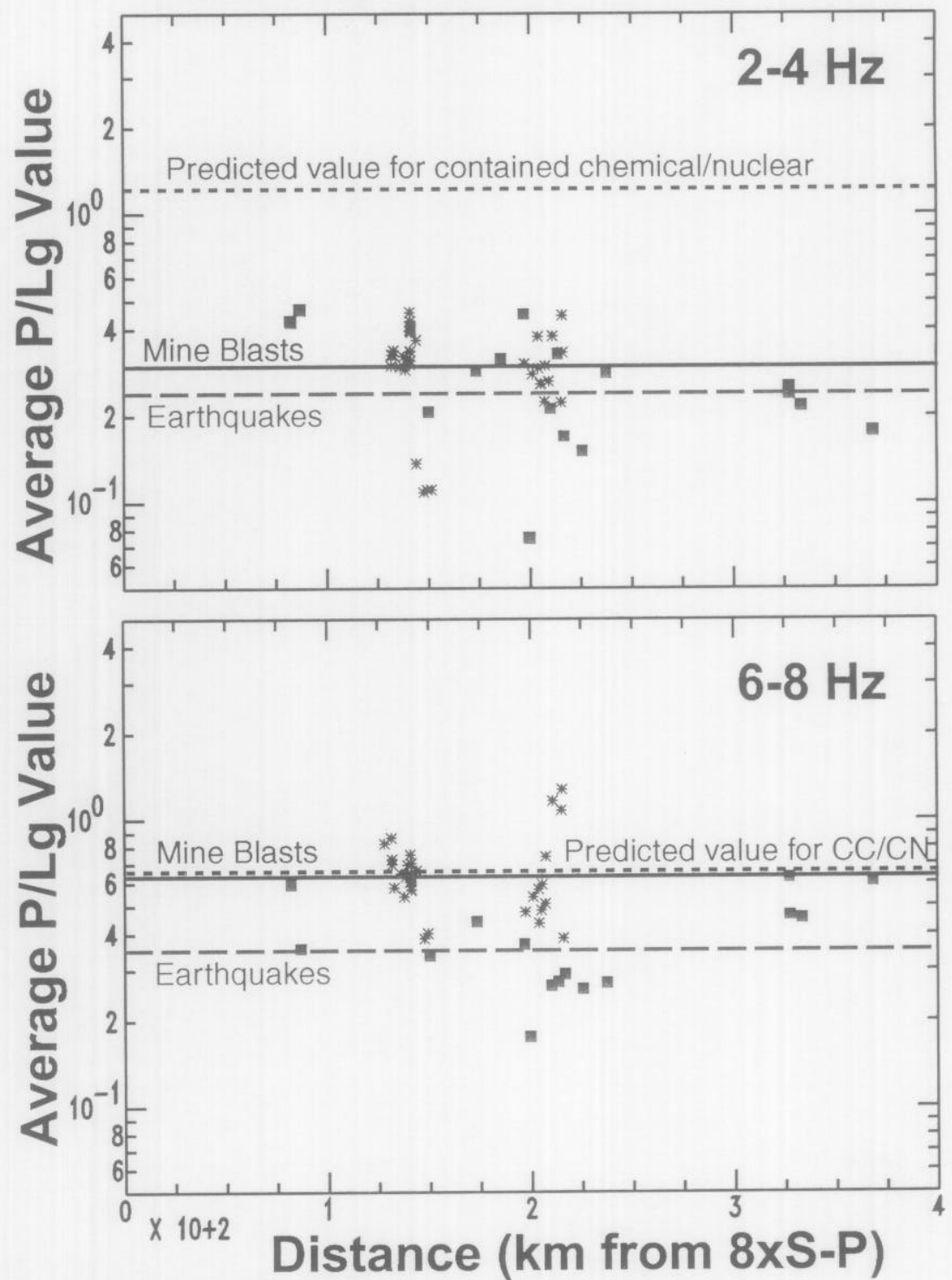

Fig. 2. These plots show an example of using mining explosions to test regional discriminants at IMS auxiliary station MDT in Morocco (after Walter et al., 1997). The map at left shows the location of the station, and a number of earthquakes and mining explosions. The plots at right show the regional seismic P to Lg discriminant values illustrating earthquake-mineblast separation at two different frequencies. Using the results of the Kazakh 1997 DOB experiment (Myers et al. 1999) and some Black Thunder experiments (Stump and Pearson, 1997) we might predict a contained chemical or nuclear test to have a P/Lg value about a factor of 4 larger than the mine blasts at $2-4 \mathrm{~Hz}$, while at $6-8 \mathrm{~Hz}$ they should be just slight greater than the mine blast. See text for discussion. 


\section{Source Phenomenology Experiment}

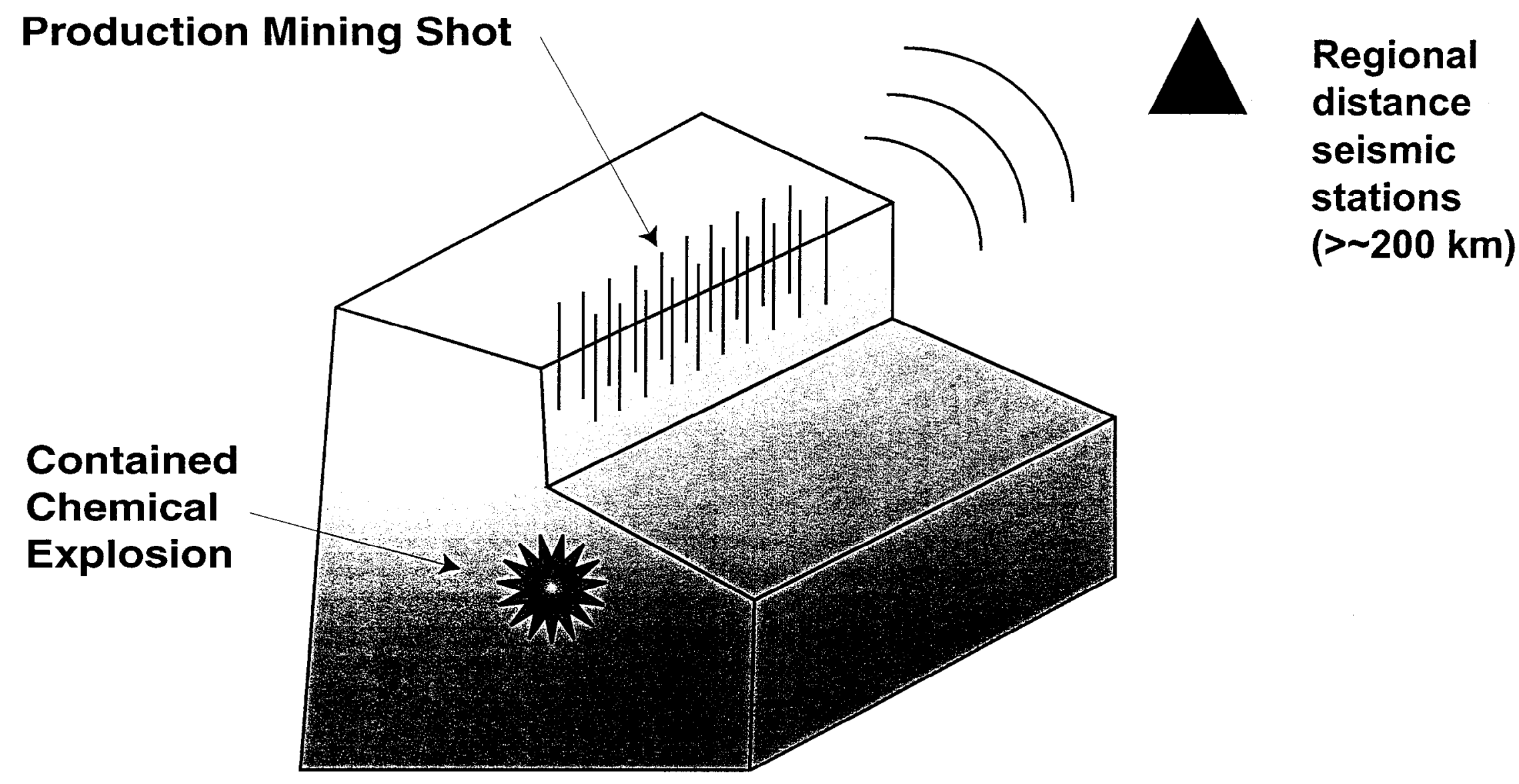

Fig. 3. This is a schematic of the basic experiment which involves detonating at least two nearly co-located explosions, both recorded at regional distances. One explosion is a standard production mining shot, which is distributed in time and space, producing significant rubble. The second shot is a contained chemical explosion at depth acting as a surrogate for a nuclear test. Both shots must be large enough to have useful signal above the noise for the common regional phases ( $\mathrm{Pn}, \mathrm{Pg}, \mathrm{Sn}, \mathrm{Lg}, \mathrm{coda}$ ) in the regional discriminant bandwidth of $1-10 \mathrm{~Hz}$. The comparison of seismic data from these two shots will provide insight into basic explosion phenomenology and will allow the use of the much more common production mining explosions for calibration. 